\title{
A Computational Approach Towards Conflict Resolution for Serious Games
}

\author{
Gordon P. D. Ingram \\ Interactions Lab \\ University of Bath \\ Bath, UK \\ g.ingram@bath.ac.uk
}

Yun-Gyung Cheong, Rilla Khaled, Corrado

Grappiolo

IT University of Copenhagen

Rued Langgaards Vej 7

Copenhagen, Denmark

\{yugc, rikh,cogr\}@itu.dk

\author{
Joana Campos, Carlos \\ Martinho \\ INESC-ID \\ IST - UTL \\ Porto Salvo, Portugal \\ \{joana.campos, car- \\ los.martinho\}@ist.utl.pt
}

\author{
Ana Paiva \\ INESC-ID \\ IST - UTL \\ Porto Salvo, Portugal \\ ana.paiva@inesc-id.pt
}

\author{
Georgios Yannakakis \\ IT University of Copenhagen \\ Rued Langgaards Vej 7 \\ Copenhagen, Denmark \\ yannakakis@itu.dk
}

\begin{abstract}
Conflict is an unavoidable feature of life, but the development of conflict resolution management skills can facilitate the parties involved in resolving their conflicts in a positive manner. The goal of our research is to develop a serious game in which children may experiment with conflict resolution strategies and learn how to work towards positive conflict outcomes. While serious games related to conflict exist at present, our work represents the first attempt to teach conflict resolution skills through a game in a manner informed by sociological and psychological theories of conflict and current best practice for conflict resolution. In this paper, we present a computational approach to conflict generation and resolution. We describe the five phases involved in our conflict modeling process: conflict situation creation, conflict detection, player modeling and conflict strategy prediction, conflict management, and conflict resolution, and discuss the three major elements of our player model: assertiveness, cooperativeness, and relationship. Finally, we overview a simple resource management game we have developed in which we have begun experimenting with our conflict model concepts.
\end{abstract}

\section{Categories and Subject Descriptors}

J.4 [Social and Behavioral Sciences]: Sociology-conflict modeling; K.3.0 [Computer Uses in Education]: General; I.2.1 [Applications and Expert System]: Games

\section{General Terms}

Theory

Permission to make digital or hard copies of all or part of this work for personal or classroom use is granted without fee provided that copies are not made or distributed for profit or commercial advantage and that copies bear this notice and the full citation on the first page. To copy otherwise, to republish, to post on servers or to redistribute to lists, requires prior specific permission and/or a fee.

FDG'11, June 29-July 1, Bordeaux, France.

Copyright 2011 ACM 978-1-4503-0804-5/11/06 ... \$10.00.

\section{Keywords}

Conflict, Serious Games, Education, Social Skill Learning, Intelligent Tutoring

\section{INTRODUCTION}

\subsection{A need for conflict resolution skills}

As societies become progressively complex and diverse, members from their populations will increasingly face situations in which their values, beliefs, needs, and goals are at odds with those of other members, leading to potential situations of conflict. The need for improving conflict resolution skills amongst the population is therefore of paramount importance, as it facilitates more peaceful, stable, and productive social interactions amongst communities. The research suggests that conflict resolution skills are best able to be integrated into social behaviours if they are acquired during childhood [21]. But the acquisition of these skills, and indeed the teaching of these skills, is hardly straightforward. We note that children acquire some conflict resolution skills through basic socialisation [22]. Specific, dedicated attempts at fostering conflict resolution skills framed within the context of education have taken the form of peer mediation training [13] (where children are trained how to resolve conflicts amongst themselves), direct teaching [11] (where children are taught via lessons, films on DVD, readings), and drama workshops [6]. While we do not dispute the effectiveness of some of these methods, in our research we wish to explore games as a vehicle for teaching conflict resolution. We believe that the affordances of games in combination with the specificities of our literature-derived player-focused computational model will create a promising environment for supporting the learning of conflict resolution behaviours.

\subsection{Serious games as a vehicle for teaching con- flict resolution}

Serious games, which we understand as games featuring nonentertainment objectives [27], are increasingly being recognised as effective and powerful tools for facilitating learning and encouraging behaviour change. Aside from mainstream 
acceptance, we have a number of specific reasons for using serious games as a vehicle for teaching conflict resolution. At a basic level, games provide us with the ability to create bounded worlds and realities [12]. Conflict falls within the class of events that is not necessarily safe or consequencefree if enacted in non-simulated environments, thus the simulated nature of game worlds is a particularly useful affordance for exploring, experiencing, and learning about conflict resolution. In addition, our focus is on the practice and internalisation of skills that are very relevant to real world behaviour, and we note that the literature on games and role-play indicates that learning achieved within gaming contexts can be transferred to real world knowledge and behaviours [19, 20, 23]. Finally, games are a ubiquitous media form of our time, and thus seem very appropriate as an intervention mechanism.

There are a number of existing serious games that already deal with topics related to conflict. The Global Conflicts series developed by Serious Games Interactive concern games set in different locations around the world dealing with major conflicts for the purpose of challenging player's beliefs and ideas about conflict. In Global Conflicts: Palestine, for example, the player plays a journalist who is collecting information for a newspaper article, and must balance trust building with information collection [3]. FearNOT! is another example of a serious game about conflict, but specifically focuses on bullying. In this game, the player is an invisible friend of a virtual character who is a victim of bullying, and the task of the player is to interact with the friend and advise him on how to cope with bullying-related problems [5]. Choices and Voices is a role-playing game in which players can experiment with peer pressure management and resistance strategies, decision making in moral dilemmas, and critical assessment of advice [1]. The interactive scenarios are integrated into a narrative, where players must make a range of decisions and consider different points of view.

All of the aforementioned games succeed in representing conflict-related experiences from which players could learn. Our approach is different, in that we focus specifically on teaching skills related to conflict resolution between parties. Further, our work is informed by sociological and psychological theories of conflict, and our model of conflict management is based on and motivated by findings from the current literature on conflict and its resolution. We will also include a comprehensive evaluation program in order to assess the educational benefits of our system on children's conflict resolution skills.

\subsection{Understandings of conflict}

Conflict can broadly be defined as a process that is initiated when two or more parties involved in an interaction perceive that one member shows or feels strong opposition to the interaction [26]. One branch of the conflict resolution research positions conflict as a problem that arises in relation to parties having different goals. For example, Deutsch states that "a conflict of interests occurs when the actions of one person attempting to reach his or her goals prevent, block, or interfere with the actions of another person attempting to reach his or her goals" [8]. Similarly, specifically referring to conflict amongst children, Shantz claims: "The outset of any conflict episode involves the blocking of one child's goal by another child" [21]. Within our own research, we are drawn to goal-based understandings of conflict, as the concept of goals forms a natural fit with the language of game design.

Yet, while the blocking of goals may be a common feature leading to many conflicts, goal blocking is neither a necessary nor a sufficient condition for conflict. For example, few people would deny that bullying constitutes as a form of conflict. But in terms of blocked goals, bullying seems hard to explain: that is, it seems artificial to claim that bullying results from victims of bullying blocking the goals of bullies, or bullies specifically setting out to block the goals of victims. More simply, bullying is an attack, which emphasises the fact that opposition is at the heart of conflict.

Defining conflict in terms of affect can also be useful. For instance, it allows us to draw distinctions between arguments, which may be affectively neutral and are not necessarily perceived as conflicts, and destructive verbal conflicts, which are arguments that provoke anger and involve attacks by one or both parties, and are perceived as conflicts. In line with this perspective of conflict, Thomas defines conflict as "the process which begins when one party perceives that another has frustrated, or is about to frustrate, some concern of his" [26]. Destructive conflict could thus be defined in terms of the potential for frustration, resulting from the desire of one or more parties to frustrate another, or a perception by one or more parties that they their concerns are being frustrated.

The literature differentiating constructive from destructive conflicts is substantial, and indicates that both detrimental and beneficial consequences arise as a result of conflict $[8,15,13]$. For example, while detrimental consequences of conflict include stress and other health problems, as well as emotional and behavioural difficulties, some beneficial consequences of conflict include enhanced autonomy and individualisation, and improved social, cognitive, and negotiation abilities [15]. We note that the development of these beneficial skills could be emphasised in the safe environment provided by a serious game.

There are some broadly accepted characteristics of conflict that are particularly helpful in conceptualising conflict from a context of game design. At base, conflict is a social interaction between opposing sides with a specific temporal duration. As such, it has much in common with narrative. Laursen and Hafen, in fact, explain the typical components of conflict in terms of vocabulary we typically associate with narrative texts: "There is a protagonist and an antagonist (conflict participants), a theme (conflict topic), a complication (initial opposition), rising action (conflict behaviors), climax or crisis (conflict resolution), and denouement (conflict outcome)" [15]. This perspective emphasises how we can understand much about the underlying structures of conflict if we envisage conflict situations as narrative scenarios.

A final point to raise in our discussion of definitions of conflict is whether to focus solely on situations in which all parties involved recognise the presence of a conflict (mutual conflicts) or whether to also focus on situations in which only one party registers the presence of conflict (unilateral conflicts). Shantz points out that many authors define con- 


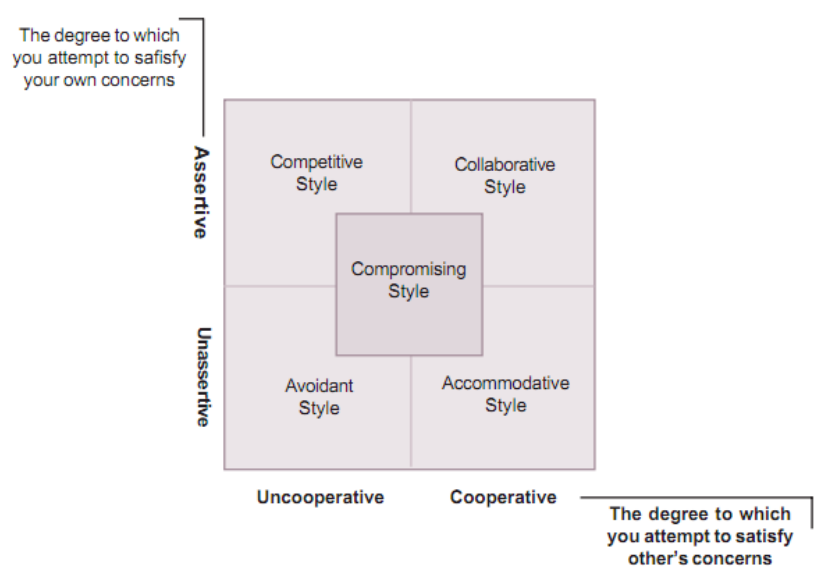

Figure 1: Conflict Management Modes ([26], [2])

flict in terms of an initial aggressive move from a first party, followed by an aggressive counter-move from a second party [21]. Such a definition is useful for the purpose of studying actual conflict behaviour. For the more applied goal of developing a broadly effective intervention tool, we appreciate that it may also be necessary to consider situations in which the aggression of both moves is not recognised by one or both parties, for example, situations in which the first party intends a move as playful but the second party interprets the move as hostile. While these situations could serve as useful targets for intervention, for our present purposes, we view them more as potential conflicts rather than actual conflicts.

\section{CONFLICT MODELS}

The conflict literature proposes various ways in which we can model different aspects of conflict. For example, Luis suggests that important characteristics of conflict situations include causes, ranging from relationship, interest, values, information, and structure (adverse and external conditions), actors, individuals or groups involved in the conflict situation, process, course of action or pathways followed, context, which may have physical, social, and cultural aspects, and type, which serves to classify conflicts based on its protagonists or causality [17].

Focusing more on the characteristics of specific conflict behaviours, Thomas suggests a taxonomy for conflict-handling modes specified in terms of two underlying dimensions: cooperativeness and assertiveness (see Figure 1) [26]. The former describes attempts to satisfy the concerns of others, while the latter describes attempts to satisfy one's own concerns. These dimensions can be combined to describe five modes of behaviour: competition, collaboration, compromise, avoidance and accommodation. The competition mode is used when one party place their interests before those of another party, and thus adhere to their own solution in solving the conflict. The collaboration mode is used when solutions that are optimal for both parties are adopted. The compromise mode is used when solutions that are acceptable for both parties are adopted. The avoidance mode is used when a party displays passive behavior and shows no interest in conflict resolution. The accommodation mode is used when one party allows the other to control the situation.
Thomas's typology suggests that in managing interpersonal conflicts, we need to consider our own goals and needs in relation to those of other parties involved, as well as how we wish to act towards other parties. We note that these conflict-handling modes also relate to conflict process and conflict outcomes.

Based on these models, and the conflict research discussed earlier, we have identified five aspects of conflict that shape how we conceptualise and operationalise conflict in our research: participants, causes, strategies, resolution, and outcome. In focusing on participants, we are interested in the role of gender, age, personality, and cultural background on conflict-related perceptions and behaviours. We currently limit causes of conflict to relationship difficulties or differences in goals. The potential set of conflict resolution strategies incorporated into our model include competition, collaboration, avoidance and accommodation. Related to strategies, which apply at an individual-level are resolutions, which apply at the situation-level, and include compromise, submission, intervention, stand-off, and withdrawal. Finally, outcomes to conflict that we plan to measure and evaluate include satisfaction levels amongst participants, material costs and benefits for participants, relationship quality between participants, and self-esteem and reputation of participants.

\section{A COMPUTATIONAL MODEL OF CON- FLICT AND CONFLICT RESOLUTION}

The conflict modeling process underlie our system consists of five phases: conflict situation creation, conflict detection, player modeling and conflict strategy prediction, conflict management, and conflict resolution. We discuss the separate phases below.

\subsection{Conflict Situation Creation}

To educate students on conflict resolution strategies, a sensible pedagogical strategy is to have them explore conflict situations, thus the system needs to be able to represent these situations. According to Deutsch [8] and Johnson and Johnson [13], conflicts can be triggered by two primary causes: goal interdependence and type of action taken.

Conflicts resulting from goal interdependence can arise when goals are negatively interdependent. If the achievement of a goal of actor $\mathrm{A}$ is based on the achievement of a goal of actor B, or actions that B has performed to achieve that goal, we consider the goals of $\mathrm{A}$ and $\mathrm{B}$ to be positively linked. If the chances of achievement of a goal of $\mathrm{A}$ decrease when the chances of achievement of a goal of B increase, we consider these goals to be negatively linked. Gratch et al. have explored goal dependency in multi-agent environments in relation to the emotional state of agents [10].

Even when goals are positively related, conflicts can arise due to types of action taken. Deutsch defines two types of actions: effective actions and bungling actions [8]. Effective actions are actions people adopt that improve their chances of achieving their goals. In contrast, bungling actions are ones that decrease people's chances of achieving their goals. Consider, for example, a household in which both parents share the goal of wanting to eat a nice dinner. Whereas the mother in this household is a skilled cook, the father is 


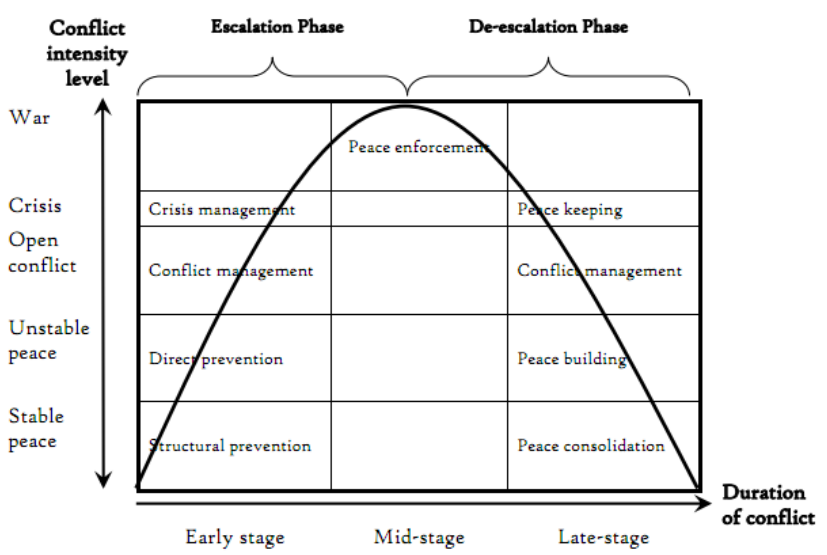

Figure 2: The Conflict Cycle (Swanstrom and Weissmann, 2005)

not, thus if he attempts to cook and produces a disasterous meal, this can be considered a bungling action. Therefore, unintentional bungling actions can threaten other people's goals, resulting in a conflict situation.

At the start of a game session, the system could either provide a setting (e.g., incompatible goals, a bad relationship, limited resources) to induce conflicts, or a non-player character (NPC) whose role would revolve around provoking players. We could also consider pitting multiple players against each other in a multiplayer game situation, in particular, those who are known to not have good relationships with one another. We believe, however, that such an approach could be detrimental towards the pedagogical goals we aim to fulfill, and also ethically problematic in terms of real world outcomes. Thus, we are conducting investigations into the benefits and disadvantages of the aforementioned multiplayer approach.

\subsection{Conflict Detection}

In order to guide players towards constructive conflict resolution, the system first needs to know when conflict occurs. As discussed in section 1.3, affect is an important component of conflict. In the course of conflict formation, one can experience a series of emotions, ranging from neutral emotions to negative emotions. As such, players' emotional responses can be used as cues to indicate escalation of conflict. Lindner links negative emotions (e.g., fear, anger, humiliation, guilt) to destructive conflict resolution strategies [16]. For instance, fear can be aroused when a person relies on avoidance or accommodation modes of behaviour, because such strategies are likely to lessen the possibility of reaching constructive solutions. Sadness is more likely to lead to compromise than anger is. Such emotions can be expressed through behavioural and physiological indicators [4]. Behavioral indicators include facial and gestural expressions. For facial expression recognition, our system tracks players' faces via a web-cam, as well as other physiological data. For gestural expression, our system uses semantic information tagged to each action taken by players, taking the advantage of virtual world. For instance, kicking and punching actions in the game world can be interpreted as expressions of anger.

Frustration, anxiety, anger, and guilt can appear in conflict and conflict resolution phases, and each of these emotions may be accompanied by other emotions. For instance, different intensities of anger can be described in terms of frustration, annoyance, irritation, furiousness, and enragement [14]. Conflict management experts Swanstrom and Weissmann proposed a conflict cycle, characterised by an escalation phase followed by a de-escalation phase, as shown in Figure 2 [24]. If the system recognises that players are furious or enraged, it could infer that players are having conflicts. On the other hand, if the system recognises that the players feel frustrated, annoyed, or irritated during gameplay, with the aid of input from the player modeling component, the system could infer upcoming conflicts in the near future. This prediction process is detailed below.

\subsection{Player Modeling and Conflict Strategy Pre- diction}

In our system, models are developed for each player. These models, in turn, are used to infer players' conflict resolution strategies, as inspired by the conflict resolution research we discussed earlier in this paper $[26,13]$.

Table 1: Conflict Handling and User model ([26])

\begin{tabular}{|l|c|c|}
\hline Management Type & Assertiveness & Cooperativeness \\
\hline Competition & + & - \\
\hline Collaboration & + & + \\
\hline Compromise & $+/-$ & $+/-$ \\
\hline Avoiding & - & - \\
\hline Accommodation & - & + \\
\hline
\end{tabular}

In a virtual environment where multiple players are involved, the system can infer the players' coping styles in a conflict situation according to Table 1 . For instance, imagine a game world with two players $A$ and $B$, where $A$ has a goal of $G_{A}$ and $B$ has a goal $G_{B}$ where $G_{A}$ and $G_{B}$ are not necessarily negatively linked. If $A$ pursues only $G_{A}$ during the game session, then the system will model him as assertive and non-cooperative, inferring that he is adopting a competitive strategy. If $A$ pursues $\mathrm{G}_{A}$ and $\mathrm{G}_{B}$ at the same time, he is labelled as assertive and cooperative, leading the system to infer that he is employing a collaboration strategy. If $\mathrm{A}$ pursues $\mathrm{G}_{B}$ rather than $\mathrm{G}_{A}$, the system labels him as nonassertive and cooperative, and thus infers that he is taking or is about to take an accommodation strategy. While the presented model uses binary representation for assertiveness and cooperativeness, a probabilistic representation can be used. For example, a player can be modeled as having an assertiveness value of 0.5 and a cooperativeness value of 0.6 , from a range of $[0,1]$ with 0 being lowest and 1 being highest. This could lead to a number of strategies - compromise, collaboration, or accommodation.

Furthermore, the system could predict the player's conflict management style during early stages of gameplay if existing player models are already available for the players. For example, the system could access player models for players A and $\mathrm{B}$ that have been derived from previous game sessions and use them to predict A and B's conflict management 
style. If B has previously been labelled as non-assertive and non-cooperative, the system would expect B to avoid conflicts in the current game session as well.

In the example above, we did not consider potential relationships between $\mathrm{G}_{A}$ and $\mathrm{G}_{B}$. But when $\mathrm{G}_{A}$ negates $\mathrm{G}_{B}$ (i.e., $\mathrm{G}_{B}=\neg \mathrm{G}_{A}$ ), this would make A non-cooperative merely by pursuing his goal at all, as helping $\mathrm{B}$ would result in $\mathrm{A}$ failing his own goal. Conversely, if $\mathrm{G}_{B}$ is a precondition of achieving $G_{A}$, A helping $B$ to reach her goal is a necessary part of A's effort to fulfil his own goal. In this case, a different policy should be applied; for instance, the system could give $\mathrm{A}$ a cooperativeness value less than a value given in usual cases where no direct causal relations apply.

Table 2: Conflict Resolution Strategy ([13])

\begin{tabular}{|l|c|c|}
\hline Management Type & Assertive & Relationship \\
\hline Forcing & + & - \\
\hline Compromise & + & + \\
\hline Withdrawing & - & - \\
\hline Smoothing & - & + \\
\hline
\end{tabular}

The player's strategy also depends on her relationship to the co-player. Imagine a case where A has previously used accommodation strategies when playing with B who bullied him. But in the current session played with $\mathrm{C}$, who is subordinate to A, A may use alternative strategies (e.g., competition or avoidance). In the work of Johnson and Johnson, people's conflict resolution strategy depend on dual elements: reaching one's own goals and maintaining an appropriate relationship with the other party [13]. Hence, the system could infer players' strategies by looking at their assertiveness level and relationship with regards to co-players, as presented in Table 2 .

Table 3: Conflict Resolution Strategy and Player model

\begin{tabular}{|l|c|c|c|}
\hline Management & Assertive & Cooperative & Relationship \\
\hline Collaboration & + & + & + \\
\hline Collaboration & + & + & - \\
or Competitive & + & - & + \\
\hline Competition & + & - & - \\
\hline Accommodation & - & + & + \\
\hline Accommodation & - & + & - \\
or Avoid & - & - & + \\
\hline Avoid & - & - & - \\
\hline
\end{tabular}

Table 3 incorporates the conflict resolution model by Johnson and Johnson [13] into the conflict handling mode proposed by Thomas [26]. Thomas's compromise strategy is not included in this table because it potentially appears across all types of player models. In merging the models of Johnson and Johnson and Thomas, we align withdrawing strategies with avoidance, forcing strategies as competition, smoothing strategies as accommodation, and compromising strategies as collaboration. Modeling the relationships among players therefore enables us to more accurately infer and predict individual players' conflict management strategies.

In summary, three essential factors underlying our player modeling approach: assertiveness, cooperation, and rela- tionships. While several studies rely on computational models to simulate the dynamics of social relationships among participants $[18,5]$, assertiveness and cooperation in relation to conflict have not yet been computationalized. As future work, we plan to devise mathematical models for calculating cooperation and assertiveness based on sociological studies and use these models to assist evaluation of conflict outcomes.

\subsection{Conflict Resolution Management Process and Intervention}

Once a conflict has been detected or anticipated, the system could intervene in the process via NPCs who provide resolution suggestions to the player. The conflict resolution process generally consists of five phases: problem definition, alternative generation, strategy selection, strategy implementation, and outcome evaluation. The first two phases fall within the scope of artificial intelligence, and require access to domain specific knowledge. Our work addresses the gap between strategy selection and strategy implementation.

Table 4: Target Strategy

\begin{tabular}{|l|c|c|c|c|c|}
\hline Conflict Model & CO & CL & CP & AC & AV \\
\hline Significant Goal & - & + & + & - & - \\
\hline Trivial Goal & + & - & & + & + \\
\hline Important Relationship & - & + & + & - & \\
\hline Limited Time & + & - & + & + & - \\
\hline Powerless & - & - & & + & + \\
\hline Requires Cooperation & - & + & + & - & \\
\hline
\end{tabular}

(CO:Competition, CL:Collaboration, CP:Compromise, AC:Accommodation, AV:Avoidance)

Although collaboration is a desirable strategy, sometimes it may be inapplicable, for example, it may be time consuming for both parties to reach an optimal solution [7, 2]. In fact, collaboration is sometimes to be explicitly avoided, for example, when the goals of one party are generally regarded as ethically problematic. Table 4 presents situations in which some strategies have advantages over others [2]. When an optimal solution is not available, a compromising strategy is preferable. A competitive strategy might be acceptable if the goal is trivial and time is limited, unless the goal requires cooperation from other parties. Accommodation and avoidance might be useful strategies for parties if they are powerless within the relevant social network. If maintenance of good relationships is of highest priority, then parties need to adopt collaboration or compromising strategies.

A player who has received no training in conflict resolution may get help from the system about options she can take. Based on this kind of model, our system could recommend conflict management strategies relevant to players' intentions and specific situations. It could also be useful to inform players of the gap between the target strategy they are attempting to employ and the strategy actually being implemented. For instance, a player who is intending to use the collaboration strategy may in fact be behaving more in line with a competitive strategy. In this case, the system could notify her of the likelihood of conflict resolution using the current approach, which might cause her to reflect and change her strategy. 


\subsection{Conflict Resolution Outcome}

As discussed in section 2, resolutions are situation-level aspects that include compromise, submission, intervention, stand-off and withdrawal. Conflicts can be resolved in ways differing from strategies intended by participants. For example, player A may initially intend to employ a collaborative strategy but may then agree to a sub-optimal solution suggested by player B, who in turn adopts a competitive strategy. As such, A resolved the conflict in a submissive fashion. Since the goal of our work is to develop a serious game which can help improve students' abilities to resolve future conflicts, it is important that we evaluate outcomes resulting from conflict scenarios and use these as feedback for the system component tasked with conflict mediation.

As mentioned earlier in this paper, outcomes can be positive or negative. Johnson and Johnson view constructively resolved conflicts as ones in which the outcome (a) satisfies all parties, (b) improves their relationship, and (c) improves the ability of parties to resolve future conflicts in a constructive manner [13]. A negative outcome may result in unpleasant emotional experiences, excessive consumption of time, and a worsening in relationship.

Specifically focused on outcomes, Deutsch identifies the following as possible consequences arising from a conflict situation [8]:

- Change in satisfaction or dissatisfaction of the parties involved

- Material benefits and costs

- Improvement or worsening of the relationship between parties

- Effects on self-esteem and reputation

- Kinds of lesson learned, etc.

Change in satisfaction or dissatisfaction could be measured either through self-reports from players or via inferences based on players' actual facial expressions and gestural responses in the virtual world. Material benefits and costs could also easily be measured in our environment, as exchange of objects and money can be continuously monitored. The remaining three items could be measured by psychological post-testing during the game evaluation phase.

\section{A RESOURCE MANAGEMENT GAME}

As an initial step towards our system, we developed a simple mini-game based on resource management conflicts. This game takes place in a single-player $3 \mathrm{D}$ environment populated by dummy NPCs and resources, in the form of fireballs, as shown in Figure 3. There are two types of NPCs differentiated by colour, reds and blues; and each has a level of happiness, ranging continuously from 1 to 0 , decreasing constantly over time. Fireballs provide NPCs with happiness ranging from 0 to 1 . The task of the player is to distribute fireballs among the NPCs under time constraints. The maximum score (i.e., degree of fair distribution) is obtained when the two populations of NPCs have an identical average happiness. The game is composed of 10 levels; at the end of

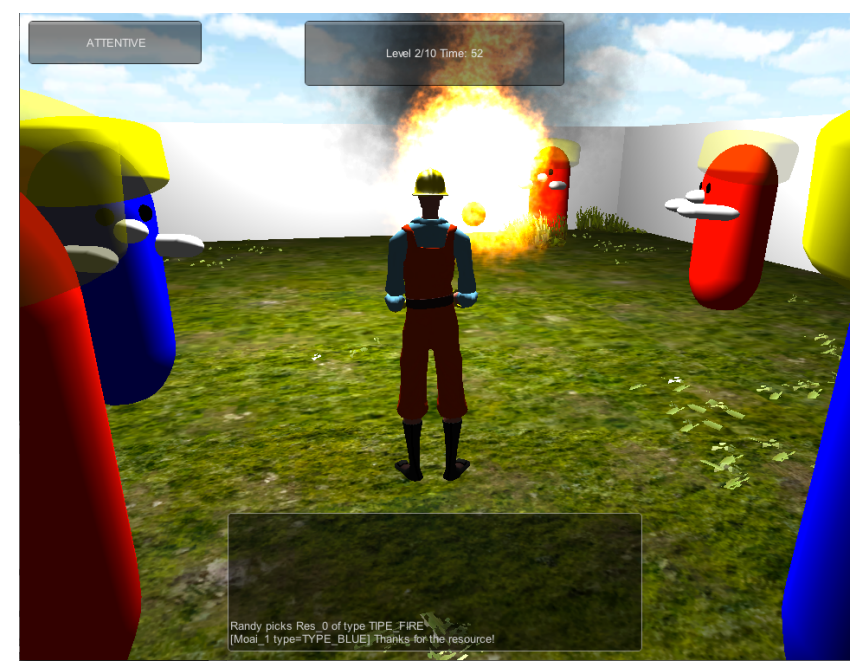

Figure 3: A screenshot of the Resource Management Game. The player character, one resource item and several NPCs are visible.

each level feedback is provided to the player in order to reward his gameplay and guide him towards even distribution. Four types of feedback are presented in the form of emoticons: positive feedback in the form of a happy face when the fairness levels increase, neutral feedback in the form of a serious face when the fairness stays the same, and two levels of negative feedback, in the form of sad and very sad faces, when the fairness levels decrease. More details can be found in $[9]$.

We are currently extending this game to represent multiple NPCs belonging to different parties. In the extended version, players will be faced with conflict situations in which they must choose between competitive strategies and collaborative strategies. A player who adopts competitive strategies will be trying to optimise the welfare of the party she belongs to, while a player adopting collaborative strategies will be trying to find optimal solutions for both parties. Further, we will replace the dummy NPCs with intelligent agents.

\section{CONCLUSIONS}

Conflict is an unavoidable feature of life. Depending on how people choose to approach conflict resolution and their skills with regards to conflict resolution management, conflicts can have negative or positive outcomes. The goal of our research is to develop a serious game in which children may experiment with conflict resolution strategies and learn how to work towards positive conflict outcomes. Our research is informed by sociological and psychological theories of conflict, and current best practice for conflict resolution.

This paper presents a computational approach to conflict generation and resolution. The conflict modeling process underlying our system consists of five phases: conflict situation creation, conflict detection, player modeling and conflict strategy prediction, conflict management, and conflict resolution. The player model contains three major elements essential for inferring conflict strategy type: assertiveness, 
cooperativeness, and relationship. When a conflict is inferred and detected, the system can suggest a desirable conflict mangement strategy relevant to the player's situation and desired outcome. As a step towards validating the relationship between the player model and conflict management strategies, we developed a simple resource management game, and have begun carrying out empirical studies of its effects on players.

Our future work includes designing and implementing a system architecture, which will serve as middleware for serious games about conflict and conflict resolution. we also intend to use group modeling techniques for understanding and predicting the behaviour and interactions of a set of players [25]. Aside from exploring solutions to technological questions, we are also in the process of investigating potential game scenarios related to conflict in light of pedagogical goals and target players' interests and needs. As an effort to understand our target group's social behavior, we have carried out ethnographic research with 60 children between the ages of 9 and 11 at two primary schools in Bath, UK. This research is particularly valuable for us with regards to game design, as it contains detailed vignettes of actual conflicts, which will be used to help us establish highly realistic conflict scenarios.

\section{ACKNOWLEDGEMENTS}

This work has been supported in part by the EU FP7 ICT project SIREN (project no: 258453).

\section{REFERENCES}

[1] Choices and voices. http://playgen.com/choices-and-voices/. PLAYGEN, accessed Jan 2010.

[2] Handbook on conflict management skill. http://www.cgg.gov.in. Centre for Good Governance, accessed Feb. 2010.

[3] Global conflict: Palestine, 2007.

[4] F. Aureli and D. Smucny. The role of emotion in conflict and conflict resolution. In F. Aureli and F. B. M. d. Waal, editors, Natural conflict resolution, chapter 10. University of California Press, Berkeley, 2nd edition, 2006.

[5] R. Aylett, M. Vala, P. Sequeira, and A. Paiva. Fearnot! - an emergent narrative approach to virtual dramas for anti-bullying education. In International Conference on Virtual Storytelling, Saint Malo, France, 2007.

[6] M. Bowman, S. K. Debray, and L. L. Peterson. Empowering students to handle conflicts through the use of drama. Journal of Peace Education, 4:1-120, 2007.

[7] M. Deutsch. Cooperation and competition. In M. Deutsch, P. T. Coleman, and E. C. Marcus, editors, The handbook of conflict resolution: theory and practice, pages 23-42. Jossey-Bass, San Francisco, CA, 2nd ed edition, 2006.

[8] M. Deutsch. Introduction. In M. Deutsch, P. T. Coleman, and E. C. Marcus, editors, The handbook of conflict resolution: theory and practice, pages 1-22. Jossey-Bass, San Francisco, CA, 2nd ed edition, 2006.

[9] C. Grappiolo, Y.-G. Cheong, J. Togelius, R. Khaled, and G. N. Yannakakis. Towards player adaptivity in a serious game for conflict resolution. In VS -Games 2011 Natural Interaction and Player Satisfaction in Games Workshop, Athens, Greece, May 2011.

[10] J. Gratch, W. Mao, and S. Marsella. Modeling Social Emotions and Social Attributions in Cognitive Modeling and Multi-Agent Interaction, Run Sun (ed.), pp 219-251. Cambridge University Press, 2006.

[11] M. T. Greenberg, R. P. Weissberg, M. U. O. Brien, J. E. Zins, L. Fredericks, H. Resnik, and M. J. Elias. Enhancing school-based prevention and youth development through coordinated social, emotional, and academic learning. American Psychologist, 58(6-7):466-474, June-July 2003.

[12] J. Huizinga. Homo Ludens: A Study of the Play-Element In Culture. Beacon Press, Boston, MA, 1955.

[13] D. W. Johnson and R. T. Johnson. Conflict resolution and peer mediation programs in elementary and secondary schools: A review of the research. Review of Educational Research, 66(4):459-506, January 1996.

[14] W. Kreidler. TeachingConflict resolution through children literature (Grades K-2). Teaching Resources, 1994.

[15] B. Laursen and C. A. Hafen. Future directions in the study of close relationships: Conflict is bad (except when it's not). Social Development, 19:858-872, 2010.

[16] E. G. Lindner. Emotion and conflict. In M. Deutsch, P. T. Coleman, and E. C. Marcus, editors, The handbook of conflict resolution: theory and practice, pages 268-293. Jossey-Bass, San Francisco, CA, 2nd ed edition, 2006.

[17] M. J. M. C. Luis. A assembleia de turma como dispositivo de mediacao e conictos. Master's thesis. Universidade de Lisboa-Faculdade de Psicologia e Ciencias da Comunicacao, 2009.

[18] J. McCoy, M. Treanor, B. Samuel, B. Tearse, M. Mateas, and N. Wardrip-Fruin. Comme il faut 2: a fully realized model for socially-oriented gameplay. In Proceedings of the Intelligent Narrative Technologies III Workshop, INT3 '10, pages 10:1-10:8, New York, NY, USA, 2010. ACM.

[19] P. Pedersen. Simulations: A safe place to take risks in discussing cultural differences. Simulation and Gaming, 26(2):201-206, 1995.

[20] E. M. Raybourn. Computer game design: New directions for intercultural simulation game designers. Developments in Business Simulation and Experiential Exercises, 24, 1997.

[21] C. U. Shantz. Conflicts between children. Child Development, 58:283-305, 1987.

[22] C. U. Shantz. Conflict in child and adolescent development. Cambridge University Press, Cambridge, England, 1992.

[23] D. W. Simkins and C. Steinkuehler. Critical Ethical Reasoning and Role-Play. Games and Culture, 3(3-4):333-355, July 2008.

[24] N. Swanstrom and M. Weissmann. Conflict, Conflict Prevention and Conflict Management and Beyond: A Conceptual Exploration. POLICY PAPER, 2005.

[25] M. Szella and S. Thurne. Measuring social dynamics 
in a massive multiplayer online game. Social Networks, 32:4:313-329, 2010.

[26] K. W. Thomas. Conflict and conflict management: Reflections and update. Journal of Organizational Behavior, 13(3):265-274, 1992.

[27] B. Winn. The design, play, and experience framework. In Handbook of Research on Effective Electronic Gaming in Education, pages 1010 - 1024. IGI Global Publication, Hershey, Philadelphia, July 2008. 